www.jmscr.igmpublication.org

Impact Factor 5.244

Index Copernicus Value: 5.88

ISSN (e)-2347-176x ISSN (p) 2455-0450

crossref DOI: _http://dx.doi.org/10.18535/jmscr/v4i3.10

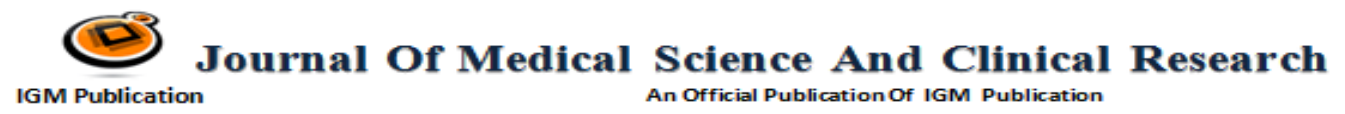

An Official Publication of IGM Publication

\title{
Role of Finger Print Pattern in Relationship with Blood Group and Gender
}

\author{
Authors \\ Dr Bindu Singh ${ }^{1}$, Dr Sajjad Jafar ${ }^{2}$, Dr Ranjan Kumar Dixit ${ }^{3}$ \\ ${ }^{1}$ Associate Professor, BRD medical college Gorakhpur Department of Anatomy, \\ ${ }^{2}$ Lecturer BRD Medical College Gorakhpur Department of Anatomy \\ ${ }^{3}$ Associate Professor BRD, Medical College Gorakhpur Department of Physiology \\ Email: Sajjadjaferkhan96@yahoo.com
}

\begin{abstract}
Introduction: Dermatoglyphics refers to the branch of science in the study of the pattern of skin ridges present on the fingers, palm and the soles of human. In 1788 JC Mayer was the first to write out basic tents of finger print analysis.

Importance of finger print in modern world is not restricted to the field of forensic and criminals application only. Dermatoglyphicsis a relatively new science, which involves the study of fine patterned dermal ridges on digits, palms and soles. Cummins and Midlo in 1926 coined the term dermatoglyphics (derma-skin; glyphiccarvings), for the scientific study of ridges.

Fingerprints are impression of pattern formed by papillary or epidermal ridges and the pattern of fingers do not change during life time or till death of the individual. Due to its effectiveness particularly in forensic medicine, the study of finger print pattern was carried out in relation between gender and blood group.

Material and Methods: In the present study 250 first year MBBS students were participated, out of which 125 were males and 125 were females in the department of anatomy, BRD Medical College Gorakhpur. Their blood groups were recorded. The finger prints of both the hands were taken on A4 size white paper using blue stamp pad. Fingerprints pattern were observed by powerful magnifying lens and recorded.

Results: In our study results shows loops are the most common pattern while arches are the least common. Loops occur more frequently in females while male have higher incidence of whorl.

Loop is predominantly found in blood group B while fingerprint pattern whorl is predominantly found in blood group $O$.

Conclusion: According to our study we may conclude that prediction of gender and blood group of a person may be possible with the study of fingerprints methods which may help in forensic medicine to identify victims and diseases.
\end{abstract}

Keywords- Fingerprints pattern, Blood groups, Gender.

\section{Introduction}

The term dermatoglyphics has its origin from Greek words "derma" means skin and "glyphics" means carving. The dermatoglyphics study was first performed by Cummins. About three thousand years ago several works was done on dermatoglyphics in China .Herschel used fingerprints for personal identification in India. ${ }^{(1)}$ Fingerprints are impression of pattern formed by papillary or epidermal ridges of the fingertips and the pattern in finger. ${ }^{(2)}$ 
A finger ridges is a raised portion of the epidermis on the digits or on the palmer and planter skin, made up of one or more connected ridge units of friction ridge skin. The ridges pattern depends upon cornified layer of epidermis as well as dermal papillae. once the ridge is formed during fetal period it will not change throughout life, until the skin was destroyed by burn ,chemicals, cuts and diseases affecting the skin..Finger print pattern are genotypically determined and remain unchanged from birth till death. ${ }^{(3)}$ Two person have identical finger prints is about one in 64 thousand millions ${ }^{(4)}$.

Four types of finger prints patterns observed in fingers are, Loops, Whorls, Arches, and mixed or Composites. ${ }^{(5)}$ The arches are the simplest pattern and loop is the most common of all the pattern. the term composite is used for combination of pattern that does not fit in to any of the above classification. ${ }^{(6)}$ Finger print are now a day's used in many purposes-It can be used to validate electronic registration in many offices and educational institutions. The characteristics patterns of epidermal ridges are differential in their definitive form during $3^{\text {rd }}$ and $4^{\text {th }}$ month of intra uterine life. ${ }^{(7)}$

The type of finger print is unique and is based on genetic characters of each individual .The secretion in the fingerprints contains residues various chemicals and their metabolites. which can be used for the forensic purpose to identify the suspected victims. ${ }^{(8)}$

Blood group system was discovered by Karl Landsteiner, in 1901. 19 major groups have been identified which vary in their frequency of distribution amongst various races of mankind .Clinically, only 'ABO'and 'Rhesus' groups are of major importance, 'ABO' system is further classified as A, B, AB, O blood group types according to presence of corresponding antigen in plasma. ${ }^{(9)}$

The genetics of blood groups is complicated by gene linkage with other characters which may be of some clinical importance eg-duodenal ulcer show a higher incidence in those with blood group
$\mathrm{O}$ than in general population and gastric cancer in blood group $\mathrm{A}^{(8-10)}$.

In the present study we are trying to find out the correlation between palmer dermatoglyphics, gender and blood group.

Dermatoglyphics offers at least two major advantages as an aid to the diagnosis of medical disorders.

The epidermal ridge patterns on hands and soles are fully developed after birth and thereafter remain unchanged for life.

Scanning of ridge patterns or recording their permanent impressions can be accomplished rapidly, inexpensively and without any trauma to the patient.

\section{Material and Methods}

The present study was carried out over a period of 1 year 6 month in anatomy department of BRD Medical CollegeGorakhpur.250 first year MBBS students (150 male \& 150 females $)$ were participated in the study voluntarily and their finger print were taken by using blue color stamp pad a supreme company size- $97 \times 160 \mathrm{~mm}$.

It is necessary to remove oil, dirt, and sweat from the skin.The hand was washed with soap and water and humidity clean off with sprit. After drying the hands, ink pad used for the impression of fingerprint patterns.

The plain white paper of A4size was kept on the table. The subject was asked to press their fingers on the blue color stamp pad and then the finger (palmer side) areas were carefully and uniformly placed on the white sheet paper .After obtaining the fingerprint patterns (Loop, Arch, Whorl, composites) were observed with the help of a powerful magnifying lens and recorded in a specially prepared format.In our study the digits were classified according to Henry's system.

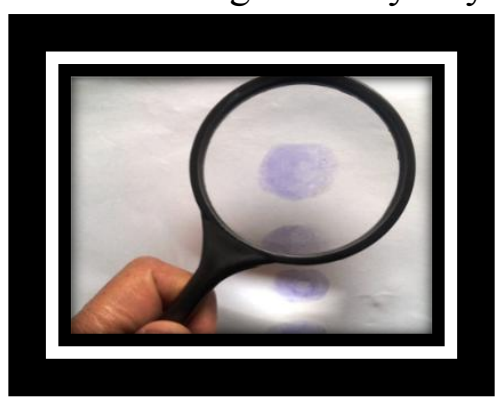



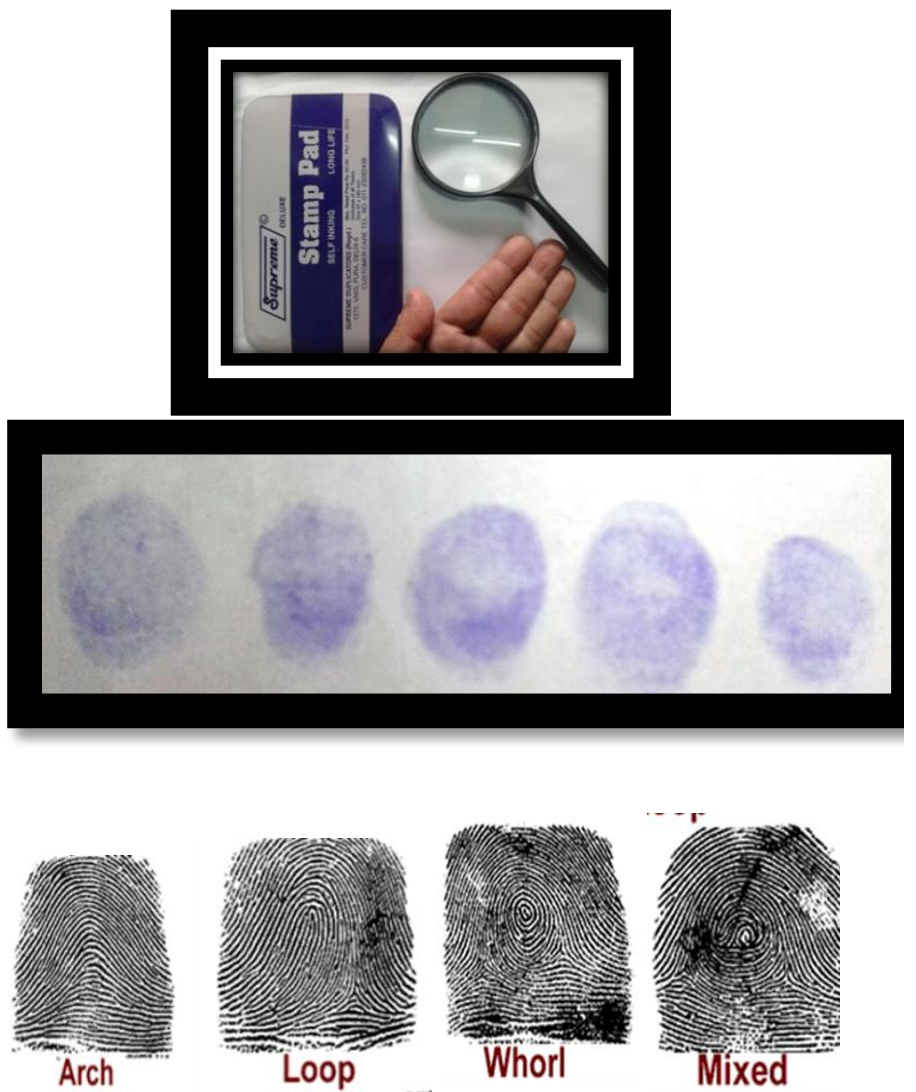

\section{Results and observations}

In the present study 250 students were participated out of which 125 were males and 125 were females. majority of the subject belonged to blood group $\mathrm{B},(41 \%)$ followed by blood group $\mathrm{A},(23.2 \%), \mathrm{O}(23.2 \%)$ and $\mathrm{AB},(12 \%)$ respectively. (Table-1)

Table 1 shows distribution of blood groups according to gender, blood group B frequency is higher in female than male and blood group $\mathrm{A}$ is higher in male than females, while female have equal ratio of blood group $\mathrm{A} \& \mathrm{O}$.

Table-1 Distribution of blood groups in male and females

\begin{tabular}{|l|c|c|c|c|c|c|}
\hline \multirow{2}{*}{$\begin{array}{l}\text { Blood } \\
\text { group }\end{array}$} & \multicolumn{2}{|c|}{ Male } & \multicolumn{2}{c|}{ Female } & \multicolumn{2}{c|}{ Total } \\
\cline { 2 - 7 } & No. & $\%$ & No. & $\%$ & & \\
\hline A & 38 & 30.4 & 28 & 22.4 & 58 & 23.2 \\
\hline B & 50 & 40 & 54 & 43.2 & 104 & 41.6 \\
\hline AB & 15 & 12 & 15 & 12 & 30 & 12 \\
\hline O & 30 & 24 & 28 & 22.4 & 58 & 23.2 \\
\hline Total & 125 & & 125 & & 250 & \\
\hline
\end{tabular}

Table 2 shows frequency of loops is higher in females $(63.68 \%)$ than males $(35.84 \%)$. Whereas whorls were more in male $(54.4 \%)$ comparison to females (25.92\%).10.4\% of arches found in females and $9.76 \%$ in males.

Table-2 Distribution of finger print patterns of all the fingers among male and female

\begin{tabular}{|l|c|c|c|c|}
\hline \multirow{2}{*}{$\begin{array}{l}\text { Types of finger } \\
\text { tip pattern }\end{array}$} & \multicolumn{2}{|c|}{ Male } & \multicolumn{2}{c|}{ Female } \\
\cline { 2 - 5 } & No. & Percentage & No. & Percentage \\
\hline Loops & 448 & $35.84 \%$ & 796 & $63.68 \%$ \\
\hline Whorls & 680 & $54.4 \%$ & 324 & $25.92 \%$ \\
\hline Arches & 122 & $9.76 \%$ & 130 & $10.4 \%$ \\
\hline
\end{tabular}

Total no of loops found in both gender in all the digits (both hand) were 1244 (49.76\%).followed by whorls 1004(40.16\%).while arches were present in a low frequency $252(10.8 \%)$.this table clearly shows that loops are more frequently found followed by whorls and Arches.(Table 3) 
Table 3 Distribution of fingerprints patterns in male and female.

\begin{tabular}{|l|c|c|c|c|}
\hline Finger print Patterns & Male & Female & Total & Percentage \\
\hline Loop & 448 & 796 & 1244 & $49.76 \%$ \\
\hline Whorls & 680 & 324 & 1004 & $40.16 \%$ \\
\hline Arches & 122 & 130 & 252 & $10.8 \%$ \\
\hline Total & 1250 & 1250 & 2500 & \\
\hline
\end{tabular}

Table 4 shows in blood group B loops are most common pattern in blood group B (76.61\%) while arches are the least common. while higher no of whorl is seen in blood group $\mathrm{O}(65.76 \%)$.male have higher incidence of whorl. Whereas arches are the least common in blood group $\mathrm{AB}(29.79 \%)$ and $\mathrm{A}(15.52)$.Loops are predominantly found in blood group B while whorls are predominantly found in blood group $\mathrm{O}$.

Table 4 Distribution of fingerprint pattern among different blood groups.

\begin{tabular}{|l|c|c|c|c|c|c|c|c|}
\hline \multirow{2}{*}{$\begin{array}{l}\text { Types of } \\
\text { pattern }\end{array}$} & \multicolumn{2}{|c|}{ Blood group A } & \multicolumn{2}{c|}{ Blood group B } & \multicolumn{2}{c|}{ Blood group AB } & \multicolumn{2}{c|}{ Blood group O } \\
\cline { 2 - 9 } & NO & $\%$ & No & $\%$ & No & $\%$ & No & $\%$ \\
\hline Loop & 305 & 53.79 & 675 & 76.61 & 59 & 15.28 & 205 & 30.78 \\
\hline Whorls & 174 & 30.68 & 180 & 20.43 & 212 & 54.92 & 438 & 65.76 \\
\hline Arches & 88 & 15.52 & 26 & 2.95 & 115 & 29.79 & 23 & 3.45 \\
\hline Total & 567 & & 881 & & 386 & & 666 & \\
\hline
\end{tabular}

\section{Discussion}

The present study shows an association between distribution of fingerprint pattern, gender and blood groups. Majority of subject in our study belonged to blood group B (41.6\%), Followed by $\mathrm{O} \& \mathrm{~A}(23.2 \% \& 23.2 \%), \mathrm{AB}(12 \%)$ groups. Percentage of loops were highest in blood group $\mathrm{B}(76.61 \%)$ and lowest in $\mathrm{AB}$ group $(15.28 \%)$ and percentage of whorls were highest in $\mathrm{O}$ blood group $(65.76 \%$ )whereas percentage of Arches in AB blood group was highest (29.79\%)and lowest in O blood group $(3.45 \%)$ which was similar to the findings of Mahajan et al (1986) and Kshirsagar et al (2001) , ${ }^{(11-12)}$ who observed higher percentage of Loop in $\mathrm{B}$ and $\mathrm{AB}$ blood groups respectively, higher percentage of whorls in $\mathrm{O}$ blood group and lowest in $\mathrm{AB}$ blood group and percentage of Arches is highest in $\mathrm{AB}$ blood group. While lower percentage in O'blood group. similar to study done by Bhardwaja, ${ }^{(7)}$ Prateek and Gowada \& Rao, there is high frequency of loop moderate of whorls and low of arches in blood group A,B and O. ${ }^{(13,14)}$ Similar to Prateek et al, in our study also found that frequency of loops is greater in females $(63.68 \%)$ as compared to a higher frequency of whorls $(54.4 \%)$ in males. similar to Sharma et al ${ }^{(15)}$ the general distribution pattern of fingerprints in our study showed high frequency of loops in blood group B in female 796 ( 63.68\%).comparison to male ;448 (35.84\%). While the whorls is higher in blood group $\mathrm{O}$ in male $680(54.4 \%)$ than female $324(25.92 \%)$. and of arches is nearly equal in blood group $\mathrm{A} \& \mathrm{AB}$ in female $130(10.45)$, male $122(9.76 \%)$. Table 4 shows Loops were highest in B blood group (76.61\%)the frequency of Whorl is highest in blood group $\mathrm{O}(65.76 \%)$ which is similar with study of Bharadwaja ${ }^{(7)}$ and arches were of higher frequency in blood group $\mathrm{AB}(29.76 \%)$ and least $\mathrm{O}(3.45 \%)$ group..

\section{Conclusion}

The present study shows that there is an association between fingerprint patterns, blood group and gender. The majority of subjects in our study belonged to blood group B. Higher number of loops is seen in blood group B in female and whorl were highest in blood group $\mathrm{O}$ in males. According to our study we may conclude that prediction of gender and blood groups of a person may be possible with the study of fingerprints methods which may help in forensic medicine to 
identify victim's .Through this study more lives can be saved due to early detection of diseases.

\section{Reference}

1. Herschel WJ.Skin Furrows of the hand .Wahul 1880;23:76.

2. Purkinje JE, physiological examination of visual organ and of the cutaneous system Brirlaree/Vratisavial Typis Universities , 1823(translated to English by Cummins $\mathrm{H}$ and Kennedy RW;Am .J.Crim Law. Criminal) 1940;31;343-356,

3. http//www.fingerprintamerica.com/fingerp rinthistory.asp.

4. Galton F,Taxtbook of finger prints, London. machmillon and co,1892.

5. VIj,k,Texbook of Forensic medicine and toxicology , $3^{\text {rd }}$ ed , New Delhi, Elsevier, 2005:89-91,

6. Subrahmanyam,R.V.In .modis medical jurisprudence and toxicology $.22^{\text {nd }}$ Ed. New delhiButterworthsIndia ,1999;71-77.

7. Bhardwaja A,Sarswat P.K.,Agrawal S.K., Banerji P. and Bharadwaj S. Pattern of fingerprints in different $\mathrm{ABO}$ blood groups Journal of Forensic medicine \& toxicology ,2004;21(2):49-52.

8. Ian Aird et al, a relation between cancer of stomach and the ABO blood groups ,British medical Journal .1953;799-801.

9. Bijlani RL, Texbook of physiology $.2^{\text {nd }}$ ed blood groups:93-94.

10. Ian Aird et al, the blood groups in relation to peptic ulceration and carcinoma of colon ,rectum, breast and bronchus, British medical journal .1969;11:315-321.

11. mahajan AA.Dermatoglyphics and ABO Blood group. Thesis submitted for MS Anatomy, Aurangabad, 1986.

12. Kashirsagar SV,etal, study of fingerprint patterns in ABO Blood group ,J AnatSoc India,2003;52 (1):82-115.

13. Dr.Prateek rastogi A study of fingerprint in relation to gender and blood group J Indian Acade Forensic Med,32(1) .
14. Gowda mst and Rao CP.A study to evaluate relationship between dermatoglyphics feature and blood groups .J Anat, society of ind.1996, 45:39.

15. Sharma P R, Gautam ,A.K.Tiwari P.K dermatoglyphics variations in five ethnogeographical cohorts of Indian populations; A Pilot study. the journal of biological Anthropology.2008;(1):57-66.

16. Subrahmanyam, R.V.In .modis medical jurisprudence and toxicology $.22^{\text {nd }}$ Ed. New Delhi Butter worths India ,1999;7177. 